\title{
The Psychoinformatic Complexity of Humanness and Person-Situation Interaction
}

\author{
Suraj Sood ${ }^{1}$ \\ ${ }^{1}$ University of West Georgia, Carrollton, GA 30117, USA \\ surajsoodx@gmail.com
}

\begin{abstract}
This paper undertakes to answer the questions of how humanness is to be defined and computationally functionalized, as well as of how person-situation interaction is to be formalized mathematically. Complexity science and psychoinformatics are the two primary fields considered in addressing these questions. A novel "psychoinformatic complexity" (PIC) paradigm is outlined and argued to be an adequate one within which to operationalize modern-day Western humanness and person-situation interaction. The paper ends with a consideration of current PIC applications, including social media analytics and humanoid robotics.
\end{abstract}

Keywords: Complex Systems, Psychoinformatics, Person-Situation Interaction, Humanness, World Wide Web.

\section{Introduction}

"To be, or not to be?" Hamlet famously inquired in [1]. "2b|| !2b?" One may formulate in the JavaScript Web programming language (albeit, without expecting one's compiler to interpret this interrogative string as such). What is the "meaning of being" ([2], p. 4)? The present paper undertakes to answer the question not of being in general, but rather that more specifically of "humanness" (i.e., the condition of human beings). Its primary thesis is that humanness and person-situation interaction as these exist in modern-day informational societies can respectively be formalized and functionalized in terms of a novel "psychoinformatic complexity" (PIC) paradigm. Both humanness and PIC will be defined to such points that the support for this argument will require.

\section{Related Work}

What is it to be human? Haslam et al. found that participants diverged when asked which attributes were unique to humans versus which were simply aspects of human nature, associating "entirely different characteristics" to each ([3], p. 28). At least semantically, therefore, the concept of humanness has been found to be not entirely unitary. However, from an a priori standpoint, human beings or (perhaps to be more specific) people may generally be said to be 
1. Physical - People's bodies are composed of matter. Further, people interact with other physical objects.

2. Biological-People breathe, eat, and drink; and a great many of them fornicate and reproduce.

3. Temporal - People are born, they live, and they die; they experience time.

4. Cultural-People are embedded in cultures characterized by unique but shared ways of being.

5. Social - People participate in societies consisting of concrete relations between themselves and others.

6. Economic - People are agents who trade goods and services with one another in marketplaces.

7. Technological - People invent and utilize tools to perform tasks they were previously unable or less able to accomplish.

8. Artistic - People express themselves through the creation of original works such as paintings and songs.

9. Intellectual - People aim to comprehend reality and achieve accurate understandings of it.

10. Moral - People have unique and shared ideas of wrong versus right action.

11. Spiritual-People seek enlightenment, wisdom, and contact with the divine or supernatural via practices such as meditation and prayer.

12. Religious - People worship what they deem as sacred (e.g., God or Gods) through rituals and organized communion.

13. Political - People negotiate and have interests that are in line or at odds with those of others.

14. Athletic - Whether for fitness or organized play, people exercise their bodies and minds.

15. Professional - People work toward particular goals, including money and satisfaction.

16. Recreational - People enjoy leisurely activities such as taking walks and attending parties.

17. Linguistic - People communicate via representational symbol systems characterized by semantics, syntax, and pragmatics.

18. Psychological - People have minds and engage in behaviors. More specifically, they think, feel, are motivated, have personalities, interact with situations, sense, perceive, experience.

While the above list provides an idea of how complex human beings are, it is arguably more relevant to personology than personality. McCrae and Costa utilized the term "personologists" ([4], p. 81) but did not distinguish such researchers from personality psychologists. Still, given that 18 . above states the core topics of psychological inquiry, one could most reasonably expect "person-centered" 
psychologists to focus on its items. These types of psychologists would thus need to include mind, behavior, cognition, affect, motivation, personality, "situationality", sensation, perception, and experience in their ultimate descriptions of who human beings are, their explanations of how said beings come to be as such, and their predictions of whom these beings are anticipated to become. For human scientists (including psychologists), the next question becomes of how the total complexity of humanness is to be subsequently operationalized.

\section{Toward a Science of Psychological Complexity}

The first approach to operationalizing humanness that this paper will consider is complexity science, or what Bar-Yam called "complex systems" [5]. Complex systems is a relatively new approach within which "relationships between parts [that] give rise to the collective behaviors of a system and how the system interacts and forms relationships with its environment" are studied (p. 24). Such a science of complex systems is additionally concerned with

1. How specifically self-organized patterns of behavior arise from interactions between parts

2. How complexity and scale are to be balanced against each other

Importantly, 1. here implicates two concepts that Bar-Yam considered core for complexity science: emergence and interdependence (p. 25). Psychologically, the question of emergence is particularly relevant in discussions of either consciousness or mind, wherein it is assumed that at least one of these phenomena emerges from a necessary biological substrate $[6,7]$ or sufficiently-constructed and activated neural network [8]. Interdependence is relevant to the study of any psychological system that consists of $n \geq 2$ parts which interact with one another. In order for complexity science to be relevant for psychology, such notions of emergence and interdependence would need to be applied to the studies of psychological mind, behavior, cognition, affect, motivation, personality, situationality, sensation, perception, and/or experience.

Complexity theory has already been applied to the formulation and troubleshooting of "real-world" global problems [5]. Thus, complexity theory may be applied within psychology at least to the extent that any psychological problem is also both complex and global. Sood elucidated various aspects pertaining to the intersection between psychology and global problem-solving, but omitted complexity science in his research $[9,10]$. Regardless, any complex phenomenon whatsoever would represent a valid topic of study for complexity science, with psycho-global problem-solving representing but one important example.

Problem-solving is itself optional for complexity science until one considers a domain such as theoretical computer science. Sipser stated the "central question of [computational] complexity theory" as being that of what makes "some problems computationally hard and others easy" ([11], p. 2). In just his way has complexity theory now been broadened to include the field of computer science. If complexity theory is of relevance to the solution of global psychological problems, then the remaining relation to be elucidated is that which might exist between psychology and computer science. Such a link exists in the form of the new field, psychoinformatics. 


\section{$4 \quad$ Psychoinformatics and Complexity}

According to Yarkoni, psychoinformatics is "an emerging discipline that uses tools and techniques from the computer and information sciences to improve the acquisition, organization, and synthesis of psychological data" ([12], p. 391). The suffix of psychoinformatics - i.e., -informatics - denotes the somewhat distinct area of informatics. Gruska described this discipline's "main task" as being "to discover, explore and exploit in depth the laws, limitations, paradigms, concepts, models, theories, structures and processes of both natural and virtual information processing worlds and to explore their phenomena as well as their interrelations, impacts and utilization" ([13], p. 6).

How is the new science of psychoinformatics to be combined with complexity theory? This question may be addressed in terms of Bar-Yam's two core concepts for complexity (which, it will be recalled, were emergence and interdependence). Hancock et al. [14] utilized an algorithm of computational complexity $O\left(N^{2}\right)$ to infer, characterize, and visualize the emotional context arising from online social discourse. Data in the form of online forum posts were mined and subsequently processed by said algorithm. In this study, emotional context was considered the emergent property of the collective behaviors of online agents discussing topics of interest to them (viz., sports such as football). Naturally, said agents could also have been considered interdependent since their discourse required more than one person (in addition to an organizing set of topics). Hancock et al.'s may thus be viewed as both a psychoinformatic and complexity study, or one of what will henceforth be termed psychoinformatic complexity $(\mathrm{PIC})^{1}$. Next, person-situation and humanness are each treated as potential candidate constructs for PIC analysis.

\section{$5 \quad$ Person-Situation Interaction and Humanness}

How is humanness to be operationalized in terms of PIC? In order for complexity science to be relevant for psychoinformatics, emergence and interdependence will need to be applied to the virtual studies of psychological mind, behavior, cognition, affect, motivation, personality, situationality, sensation, perception, and/or experience. Within psychology, Freud was the pioneer of personality vis-à-vis mind as much as Skinner was the same for behavior [6]. Affect has been addressed by psychologists via the five factor model (FFM) constructs of Extraversion and Neuroticism; cognition was included in Kelly's personal construct [15] and Dweck and Leggett's social-cognitive [16] theories. Lastly, experience, meaning, and motivation have been taken up by third force theorists such as Kelly, Maslow [17], and Rogers, as well as by positive psychologists Proctor, Tweed, and Morris [18].

In spite of the above, it remains an open question whether psychologists have fully accounted for humanness specifically in terms of person-situation interaction. The best-established scientific construct that is closest to "person" is personality.

\footnotetext{
${ }^{1}$ In addition to emotional context and user behavior, experience was arguably also among Hancock et al.'s psychological topics of study (given that online forum posts are a rich, virtual source of such raw, phenomenological data).
} 
Situations, on the other hand, have no corresponding term denoting situationality. ${ }^{2}$ In any case, at present, what remains most incomplete is the integration of these understandings into suitable informatic contexts. How might this be achieved for both person-situation interaction and psychological humanness?

\subsection{Person-Situation Mathematics}

Personality has been defined by Pervin as involving 1) "an emphasis on defining and understanding individual differences" and 2) "an emphasis on the ways in which the various parts of the person are organized" ([20], p. 100). It has already been said that situationality has not yet received a corresponding framing by psychologists. For this paper's purposes, person-situation interaction is defined as an enactive function equaling the totality of all mental and behavioral structures (i.e., states and traits) and processes. This formulation falls under the scope of Pervin's second definition just stated. In the style of Lewin's field theory of behavior-wherein $B e=F[P, E]$ (i.e., "Behavior $=$ Function of person and environment") $([21]$, p. 878) - it is expressible as

$$
F[P, S]=\left[S t_{T, S e}, P C\right]_{M, B}
$$

Where $P$ equals "person", $S$ equals "situation", $S t$ equals "structure", $T$ equals "trait", $S e$ equals "state", $P C$ equals "process", and $B$ equals "behavior" [22]. (Traits and states are treated as distinct types of psychological structures.) With respect to enactivism, Varela, Thompson, and Rosch asserted that "the organism both initiates and is shaped by the environment...organism and environment [are] bound together in reciprocal specification and selection" ([23], p. 174). All that remains for the present psychological discussion is to substitute "organism" and "environment" with "person" and "situation", respectively.

According to (1), $F[P, S]$ is a whole composed entirely of parts $S t_{M S e}, S t_{B S e}, S t_{M T}$, $S t_{B T}, P c_{M}$, and $P c_{B}$, which respectively denote "mental states", "behavioral states", "mental traits", "behavioral traits", "mental processes", and "behavioral processes". The kind of person-situation interaction expressed through (1) - which has been formalized to render the construct more applicable within mathematical, theoretical, and computational contexts - is thus distinctly psychological in accommodating two of psychology's highest-level topics of study: mind and behavior.

Virtual personality has been suggested by Montag, Duke, and Markowetz as being determinable via psychoinformatic methods such as data-mining and tools primarily in the form of algorithms [24]. Another possibility is to operationalize virtual humanness as a Web-based program function, since the World Wide Web is a subset of the Internet (which, itself, is a subset of computing). A speculative example of how humanness might be programmed into the Web will now be suggested.

\footnotetext{
${ }^{2}$ It could perhaps be inferred from this latter fact that psychologists presently understand personality better than situationality. For a defense of such a view (as well as an attempted reversal of its implications for the current state of psychological research), see [19].
} 


\subsection{Computational Humanness}

In the JavaScript programming language, "do...while" is a distinct type of looping conditional that runs so long as some specified condition continues being met. An example of such a loop and its output are as follows

\section{do...while loop}

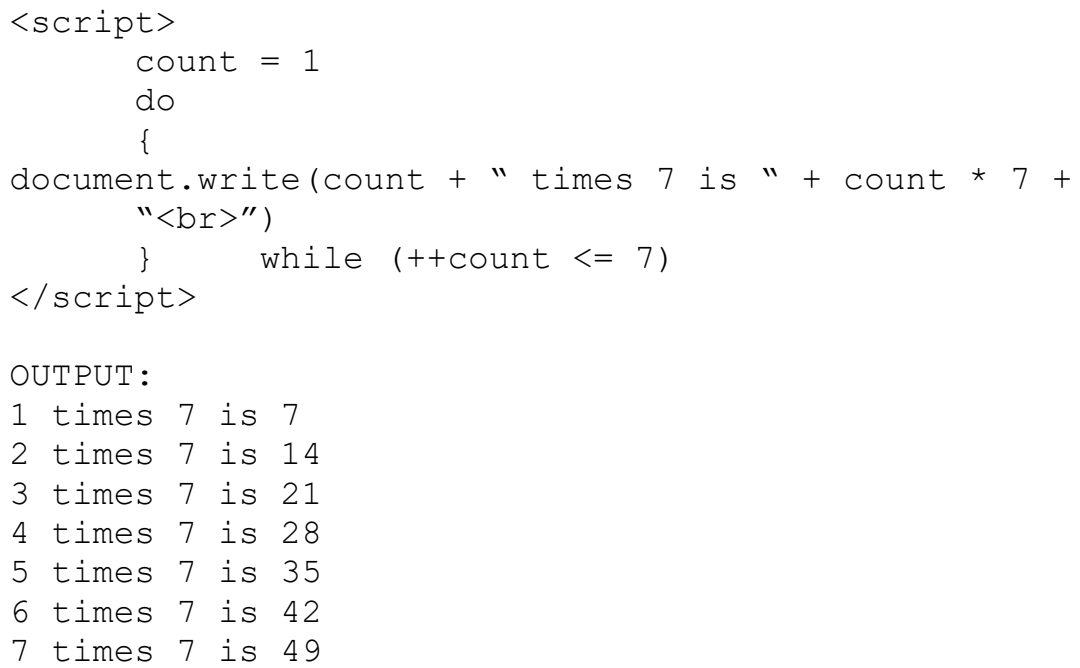

For the purpose of digitally simulating humanness, a new such conditional- "be" (in the interest of capturing the human's being) — is now proposed. Substitute "do" in the above do...while loop with "be", such that the below JavaScript loop would follow

"be...while" loop

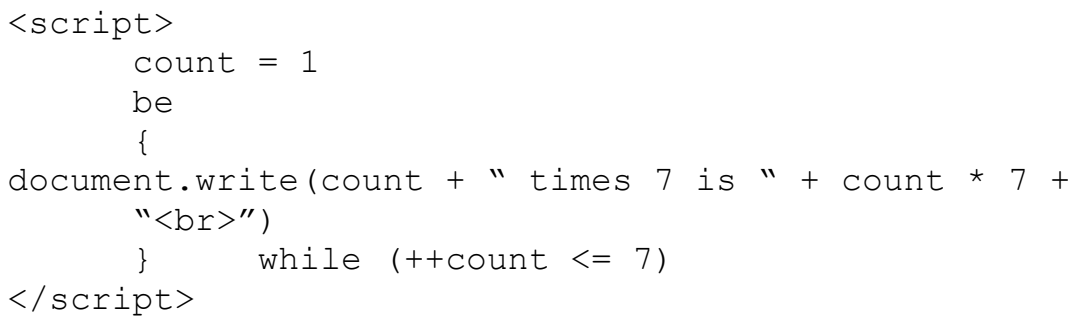

It must first be acknowledged that humanness' essential features-cognition, affect, behavior, etc. - would each need to be passed through be (probably as parameters or arguments). If this were done, then perhaps humanness could begin to be simulated computationally in the PIC sense. Be's output would need to be an emergent property of its interdependence with the other parts of a program it is situated within; said "other parts" would include any subject or object a person is expected to interact with. Above, be is the be...while loop's chief operator. 


\section{Conclusion}

In this paper, the groundwork has been laid for an interdisciplinary program termed psychoinformatic complexity (PIC). PIC combines psychoinformatics and complexity theory to render the complex virtual aspects of humanness scientifically investigable. Two of the most directly-relevant areas of application for this new field include healthcare and information technology (IT). An existing example of psychoinformatic technology is the Android app Menthal, which was developed by Andone et al. [25]. Users of Menthal input their personalities (via a short Big Five assessment) and are prompted to rate their moods every 12 hours. The latter data is stored and represented to users in an app-native calendar where they could perceive their moods each day during a given month and recognize their weekly, monthly, or even yearly mood patterns/trends. Personality itself has been measured psychoinformatically via algorithms which assess virtual users' personalities based on their online behaviors.

Personality represents the most-assessed psychological construct via psychoinformatics and its associated technological methods. Yet, of course, the complexity of humanness includes more than personality; it additionally includes mind, behavior, situationality, affect, cognition, motivation, perception, sensation, and experience. Possibly the most promising technology which could fully capture this richness of humanness is virtual reality (VR), which has so far been integrated successfully with attempts to, e.g., alleviate phobias, substance use disorders, PTSD, stress, and pain. Augmented reality (AR) has also seen success in mobile applications such as Pokémon GO and Facebook Messenger (for the latter, in its "face filters").

Open Cog's humanoid robot "Sophia Hanson" also deserves mention for being among the most successful attempts to date in the creation of a humanoid robot. Sophia's body consists only of the human female's upper-torso and limited ability to interact with humans, however; its physical complexity thus falls short of at least half of the biological human's body.

Finally, Neumann et al. [26] developed and implemented a psychoinformatic method to predict whether Twitter users were "automated" (i.e., were bots) or "non-automated" (were human users). This Sirius team aimed to map Myers-Briggs personality type onto virtual bots constructed to partake in two economic games: the prisoner's dilemma and power-to-take [27]. The PIC of humanness and person-situation may thus also be extended to include "botness" and bot-situation interaction. To facilitate new understandings of these relatively less-explored areas, it is suggested that state-of-theart human-computer interaction methods [e.g.: 28, 29, 30] be consulted for guidance.

\section{Acknowledgements}

The author thanks Drs. Eric Dodson, Marie-Cecile Bertau, and Andi Winderl for providing the opportunities to develop this paper. 


\section{References}

1. Shakespeare, W.: Hamlet, http://www.opensourceshakespeare.org/views/plays/play_view.php?WorkID=hamlet\&Sco pe=entire \&pleasewait $=1 \& \mathrm{msg}=\mathrm{pl}$, last accessed 2018/6/21.

2. Heidegger, M.: Being and time. State University of New York, Albany, NY (1953).

3. Haslam, N., Bastian, B., Bissett, M.: Essentialist beliefs about personality and their implications. Personality and Social Psychology Bulletin 30, 1661-1673 (2004).

4. McCrae, R., Costa, P.: Validation of the five-factor model of personality across instruments and observers. Journal of Personality and Social Psychology 51(1), 81-90 (1987).

5. Bar-Yam, Y.: Making things work: Solving complex problems in a complex world. NECSI/Knowledge Press, Cambridge, MA (2004).

6. Henriques, G.: A new unified theory of psychology. Springer: New York, NY (2011).

7. Wilber, K.: Sex, ecology, spirituality: The spirit of evolution. Shambhala Publications: Boston, MA (2000).

8. Tryon, W.: Neuroscience and psychotherapy: Network principles for a unified theory. Academic Press: London, U.K. (2014).

9. Sood, S.: Global existential topics for the $21^{\text {st }}$ century: Psychology and ethical being, https://www.academia.edu/23957227/Global existential topics for the 21st century Psy chology_and_ethical_being, last accessed 2018/6/22.

10. Sood, S.: Global problem-solving and ethics: A theoretical and practical analysis. International Journal of Global Environmental Issues, in press.

11. Sipser, M.: Introduction to the theory of computation. PWS Publishing Co.: Boston, MA (1997).

12. Yarkoni, T.: Psychoinformatics: New horizons at the interface of the psychological and computing sciences. Current Directions in Psychological Science 21, 391-397 (2012).

13. Gruska, J.: A perception of informatics, https://westga.view.usg.edu/d21/le/content/1411076/viewContent/24151440/View, last accessed 2018/6/21.

14. Hancock, M., Rajwani, S., Lo, C., Sood, S., Kresses, E., Bleasdale, C., Dunkel, N., Do, E., Rees, G., Steirs, J., Romero, C., Strohschein, D., Powell, K., French, R., Fedosenko, N., Casimir, C.: Field-theoretic modeling method for emotional context in social media: Theory and case study. In: Schmorrow, D., Fidopiastis, C. (eds.). Augmented Cognition 2015, LNCS, vol. 9183, pp. 418-425. Springer, Cham (2015).

15. Kelly, G.: Clinical psychology and personality: The selected papers of george kelly. John Wiley \& Sons, Inc.: New York, NY (1969).

16. Dweck, C., Leggett, E.: A social-cognitive approach to motivation and personality. Psychological Review 95(2), 256-273 (1988).

17. Maslow, A.: A theory of human motivation. Psychological Review 50, 370-396 (1943).

18. Proctor, C., Tweed, R., Morris, D.: The Rogerian fully functioning person: A positive psychology perspective. Journal of Humanistic Psychology 56(5), 1-28 (2015).

19. Rauthmann, J., Sherman, R., Funder, D.: Principles of situation research: Towards a better understanding of psychological situations. European Journal of Personality 29, 363-381 (2015).

20. Pervin, L.: Personality. In: Kazdin, A. (ed.). Encyclopedia of psychology, vol. 6, pp. 100106. American Psychological Association: Washington, DC (2000).

21. Lewin, K.: Field theory and experiment in social psychology: Concept and methods. American Journal of Sociology 44, 868-896 (1939). 
22. Sood, S.: Enactive, integrative personality and the temperament-personality-character matrix,

https://www.academia.edu/34283489/Enactive_integrative_personality_and_the_tempera ment-personality-character_matrix, last accessed 2018/6/22.

23. Varela., F., Thompson, E., Rosch, E.: The embodied mind: Cognitive science and human experience. The MIT Press: Cambridge, MA (1991).

24. Montag, C., Duke, E., Markowetz, A.: Toward psychoinformatics: Computer science meets psychology. Computational and Mathematical Methods in Medicine (2016).

25. Andone, I., Blaszkiewicz, K., Trendafilov, B.: Menthal - Running a science project as a start-up, $\quad$ https://www.researchgate.net/publication/304023331_Menthal__Running_a_Science_Project_as_a_Start-Up, last accessed 2018/6/21.

26. Neumann, S., Li, C., Lo, C., Lee, C., Rajwani, S., Sood, S., Foster, B., Hadgis, Y., Michaels, F., Ahmed, A., Bernobic, N., Hollander, M.: Content feature extraction in the context of social media behavior. In: Schmorrow, D., Fidopiastis, C. (eds.). Augmented Cognition 2017, LNCS, vol. 10284, pp. 558-570. Springer, Cham (2017).

27. Neumann, S., Sood, S., Hollander, M., Wan, F., Ahmed, A., Hancock, M.: Using bots in strategizing group compositions to improve decision-making processes. In: Schmorrow, D., Fidopiastis, C. (eds.). Augmented Cognition 2018. LNCS, vol. 10916, pp. 305-325 (2018).

28. Li, S., Karatzoglou, A., Gentile, C.: Collaborative filtering bandits, https://arxiv.org/pdf/1502.03473.pdf, last accessed 2018/9/26.

29. Kar, P., Li, S., Narasimhan, H., Chawla, S., Sebastiani, F.: Online optimization methods for the quantification problem, https://arxiv.org/pdf/1605.04135.pdf last accessed 2018/9/26.

30. Korda, N., Szörényi, B., Li, S.: Distributed clustering of linear bandits in peer to peer networks, https://arxiv.org/pdf/1604.07706.pdf, last accessed 2018/9/26. 